Jadwiga Tomalkiewicz

\title{
PLACE VOCABULARY PROJECT ,SCHOOLS IN WARSAW AND BEYOND WARSAW"
}

The Place Vocabulary Research Project is an international cross-cultural study of the ability of thirteen?year-olds from various countries to identify fifty highly visible places on an oval projection outline map of the world. The theoretical premise is that students will respond to the test on the basis of their previous school experiences and general knowledge. The goal is to measure this cognitive ability and to note whether it is universally attainable.

The test (Fig. 1) was in no sense a competition, yet, as might be expected, countries varied considerably in the range of performance by their students. It is necessary to look at the data to observe any meaningful patterns and to attempt to interpret and understand whatever correlations exist. The range of scores for the participating countries is given in Table 1.

The highest level of achievement was reported by Poland. The fact that nearly three-fourths of the students scored higher than 80 percent correct responses indicates a realm of possibility for thirteen-year-old students. Iraq, Japan, New Zealand and Norway also had high scores, but in each of these instances the sample population was small in size and not representative of an entire country.

The scores from Ireland and the Netherlands closely appruximate each other. Although they can be considered European neighbours, they still represent different language groups and genetic backgrounds.

Canada and the United States have patterns like those of Western Europe but at somewhat lower levels of performance. Those familiar with the startus of geography in the schools of these two countries might expect Canadian students to do better than their neighbours to the south, and they did. In both Canada and the United States, great regional variations were demonstrated.

Nigeria and India, both having school systems descended from a British model, had good statistical studies but their scores differed con- 
siderably. India, in keeping with its large population, tested over 5,000 students. Note that the range of scores from India approaches that of a Bell curve of normal distribution. The same is true for Canada. In Nigeria it was demonstrated that low performance correlated with students who were not taking geography as a separate subject.

Countries referred to as "developing nations" turned in the largest proportions of students in the low range of scores. Notice the similarity in scores from the Latin American countries. That the scores of Brazil, Mexico and Venezuela should be so similar lends a certain credence to the test results 1 .

\section{ORGANIZATION OF STUDIES}

Studies of the knowldge of geographic place vocabulary on a world outline map were conducted in sample schools during November and December 1979. The tests covered 302 students of the 7 th grade of primary school. The sample contained 150 boys (M) and 152 girls (F), and the tesits were carried out in fourteen classes of ten schools. Of the 302 subjects, $173(57.28 \%)$ were from schools in the city of Warsaw and the remaining $129(42.72 \%)$ represented schools in small towns and rural areas. The schools were grouped, in this report, as "schools in Warsaw" and "schools beyond Warsaw". This sample was determined in order to represent Polish schools from various environments and an analysis of the results showed that scores obtained were dependent on the location of the school.

Eight of the ten schools in which the tests were conducted had $100-1000$ students and the other two had over 1000 students. Teachers of goeography for classes in the study are employed in the schools permanently. Students born during the year 1966 were tested; they were generally in the 7 th grade.

\section{COLLECTIVE TEST RESULTS}

The collective results of testing are shown as they are reflected in schools in Warsaw and those beyond Warsaw. Over $71 \%$ of the 302 subjects scored in the range of 41.50 ( $71.85 \%$ correct answers); $15 \%$ had scores of $31-40$. The results must be considered as satisfactory. The distribution of scores has been calculated for the total sample as well as for schools in Warsaw and schools beyond Warsaw. Essential differences

1 Robert N. Saveland, Report on the Place Vocabulary Research Project, The University of Georgia, USA, 1980. 
between the achievement of students from schools in Warsaw and those from beyond Warsaw could then be identified. Significant differences between the achievement of boys and girls did not occur.

Data about the konwledge of specific oceans and seas, countries and cities on the world map are found in the analysis of errors (below).

\section{ANALYSIS OF ERRORS}

Interesting data was obtained by an analysis of errors made by students in their recognition of selected oceans and seas, countries and cities on an outline world map. The analysis allowed the identification of the least known items.

Analysis of the data shows that Poilsh students made most mistakes in recognition of the position and naming of cities $(18.06 \%$ of. incorrect answers). The difference between the numbers of mistakes made by students in Warsaw and those from schools in small towns and villages appears significant. Subjects from schools beyond Warsaw made significantly more mistakes, $26.72 \%$, as compared to subjects in Warsaw schools, who averaged $11.61 \%$ errors. Warsaw students made over $21 \%$ errons only in one case, that of identifying Johannesburg, while students from schools beyond Warsaw made $58^{0} \%$ errors for the same city. Both groups achieved the best results in knowing the name and location of Moscow. The Warsaw group made $0 \%$ mistakes and the beyond Warsaw made $2.3 \%$ ( 3 mistakes).

Students from schools beyond Warsaw made a large number of errors in locating and naming the following cities:

$\begin{array}{llll}\text { Calcutta } & 62.0 \% & & \text { Rio de Janeiro } 35.6 \% \\ \text { Johannesburg } & 58.1 \% & \text { Sydney } & 34.9 \% \\ \text { Cairo } & 44.2 \% & \text { Mexico City } & 22.6 \%\end{array}$

Somewhat fewer mistakes were made in the naming of countries, a total of $14.5 \%$. In this part of the test, subjects from beyond Warsaw made far more mistakes $(20.40 \%)$ than those from Warsaw $(10.24 \%)$. In the group of schools in Warsaw over $20 \%$ of the mistakes were made identifying the countries of Nigeria $(32,90 \%)$, Indonesia $(24 \%)$, Colombia $(23 \%)$, and Peru $(23.70 \%)$. In the group of schools beyond Warsaw, a significantly greater percentage of mistakes appeared, for example, for Indonesia, 44.2\%. Also having over $40^{0} \%$ incorrect answers were Nigeria, Ethiopia, and Algeria.

The smallest number of errors occurred in the recognition and naming of oceans and seas, $5.17 \%$, though twice as many errors were 
made by subjects from beyond Warsaw. The most difficult item in this section was the location of the Caribbean Sea, $7.9 \%$ incorrect.

By grouping names of countries and cities according to continents, it could be seen that the best known countries and cities were on the European continent, over $94 \%$ correct answers. This was observed in the schools in Warsaw and in those beyond. The poorest results were achieved by subjects in the correct naming of countries and cities in Africa, with $74.09 \%$ correct answers given.

It is emphasized that, when comparing the schools, the correlation between the location of the school and the results on the tests can be noted. This correlation points to the deficiency of the schools existing in small cities and villages.

Apart from this, some of the poor results in the test on continents are due to the fact that the test had not been adjusted to the curriculum of Polish schools. A considerable percentage of the mistakes were made by subjects from schools beyond Warsaw in the naming of countries and cities in Africa, over $37 \%$ of the incorrect answers. As noted in the Organization of Studies, the geographic theme of this continent is the basis of teaching only in the 8th grade.

CORRELATION BETWEEN TEST RESULTS AND THE NUMBER OF HOURS OF TV VIEWING

For the purpose of our analysis, TV viewing by subjects was ranked in division of 10 or less hours, $11-20$ hours, $21-30$ hours, and 31 or more hours per week. The data shows that $43 \%$ of the subjects watch TV up to 20 hours weekly, $24 \%$ up to 30 hours per week, and $28 \%$ up to 10 hours per week. The amount of $\mathrm{TV}$ viewing is almost the same for subjects in schools in Warsaw and in those beyond Warsaw. No correlation was observed between test scores and the amount of $\mathrm{TV}$ viewing. Students who did well and those who did poorly are to be found in the high TV viewing range (20-31 hours weekly), as well as those who watched TV for 10 hours or less per week.

To test the reliability of the data about hours of TV viewing per week as reported by the subjects, the following actions were taken: students from one school were given TV programmes I and II from Poland and asked to underline the programmes which they watched during the week. A tabulation was made dividing the duration of the above-mentioned programmes by the number of days in a week. This tabulation was compared with hours reported by subjects and it was determined that they reported their TV viewing accurately. 
TV programmes watched most often were:

1. Newsreel

2. "The Afternoon of Knowledge and Fantasy"

3. The Club of the Six Continents

4. Nature films, e.g., „Volcanoes of the World”, „The Biggest Rivers of the World", „Amimals of the Taiga and Tundra”, etc.

5. Educational films (programmes for schools are adjusted to the curriculum of the detailed subjects)

6. Films with a travel theme, commentaries, e.g., „Alpinistic Expeditions", "Commentaries About the Explorations in the Arctic and Antarctic".

Recapitulating, it may be judged that the amount of time spent by thirteen-year-olds in watching $\mathrm{TV}$ is too large - three to six hours daily. The influence of television viewing on the psychophysical development of the young student cannot yet be precisely answered.

\section{TRAVEL EXPERIENCE}

For the sample of 302 students, it was determined that $107\left(35.4^{0} / 0\right)$ were designated as having had travel experience. The proportions are different for schools in Warsaw nad those beyond the city.

Further analysis shows that of the 173 students, as many as 92 $(53.1 \%)$ had travelled outside Poland. The subjects had been in GDR (East Germany) (34), Czechoslovakia (16), USSR (11), Bulgaria (10), Hungary (9), Roumania (6) and Italy (5). These are all European countries and, in the majority, socialist. In addition to the above-mentioned countries, subjects in Warsaw schools had also travelled to Greece, Austria, Sweden, Belgium, Turkey, West Germany (FRG), and two had travelled to the United States. The greater possibilities of seeing different countries are for students in Warsaw schools, than for those from communal schools and small towns beyond Warsaw. As for the schools beyond Warsaw, only 11.7\% (15 students) had travelled abroad. 'These students were all located in one primary school: they had visited GDR (7), USSR (4), Czechoslovakia (3), and one had been to Hungary and Bulgaria. None of the subjects from other schools beyond Warsaw had travelled outside Poland. The remainder of the subjects $\left(46.9^{9} \%\right)$ had not travelled outside Poland, but had been to different tourist locations in the country.

An analysis of statements by subjects in Warsaw schools shows that they most often went to the following voivodships: Szczecin and Gdansk (situated on the Baltic Sea), and the voivodship of Nowy Sącz, which 
is located in the Carpathian Mountains. Over twenty subjects go to these voivodships. Central, eastern, and western voivodships of Poland have not been visited by the subjects.

Students (more than 20) from schools beyond Warsaw go with the greatest frequency to Warsaiw since it is the capital city of Poland; and then to the voivodships of Gdansk and Nowy Sącz $(11-20)$. The voivodships of Szczecin and Kraków are also visited quite often (6-10). Less than 5 students knew the voivodships of Koszalin, Elbląg, Olsztyn, Ciechanów, Płock, Łódź, Częstochowa and Katowice. All of the voivodships mentioned are characterized by the attractive aspects of their locality. The voivodships of eastern, western, and south-western Poland were not mentioned by the subjects. Travel experiences of the subjects were directed either to the mountain regions, places situated at the foot of the mountains, or to the seaside areas.

Although correlations were not examined mathematically, it can be observed that subjects who did not have travel experiences achieved poorer results in the knowledge of place names on a map of the world. Travel and performance are not equivalent in meaning, however, for only in a few cases did countries visited by the subjects appear as an item on the test.

\section{CONCLUSIONS AND FINAL POSTULATES}

(1) General results of testing of the knowledge of selected oceans and seas, countries, and cities on a world map among a group of subjects born in 1966, are satisfactory. Over $72 \%$ of the students tested achieved scores in the range of $41-50$ correct answers.

(2) Useful information can be provided for teachers of geography by an analysis of errors. Errors made indicate that the subjects' command of knowledge of several countries and cities calls for more review in class.

(3) All of the information gathered during the testing indicates a clear correlation between performance on the test and the location of the school. The best results were achieved by subjects in the city schools.

(4) Results of the tests are interesting, but the correlations between test scores and TV viewing, as well as travel experience, are difficult to interpret.

(5) The number of errors in the naming of the selected countries and cities on the world map is shocking and difficult to explain. We suggest the continuation of testing of this sort along with the under- 



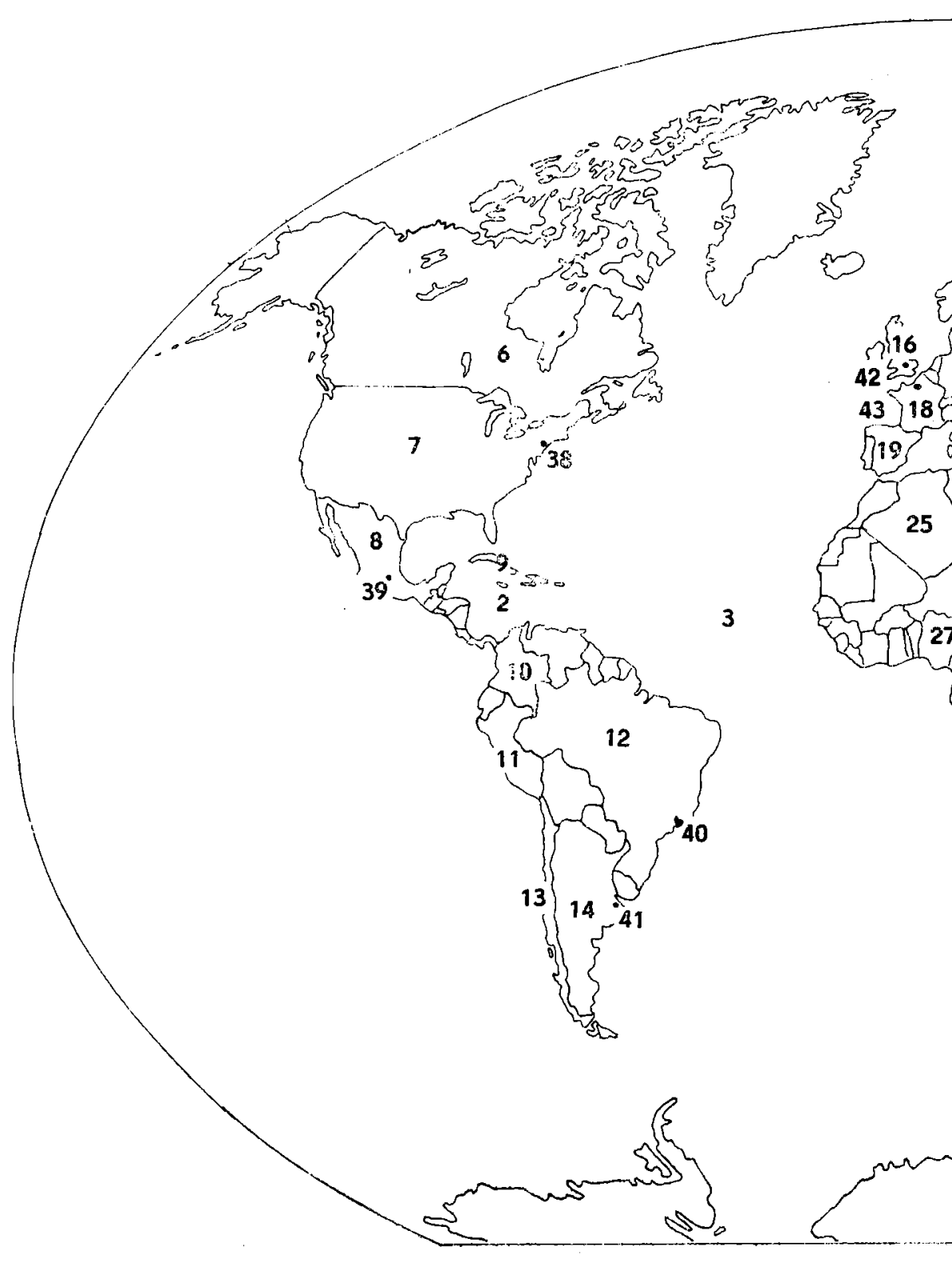

Fig. 1. Place vocabulary project 


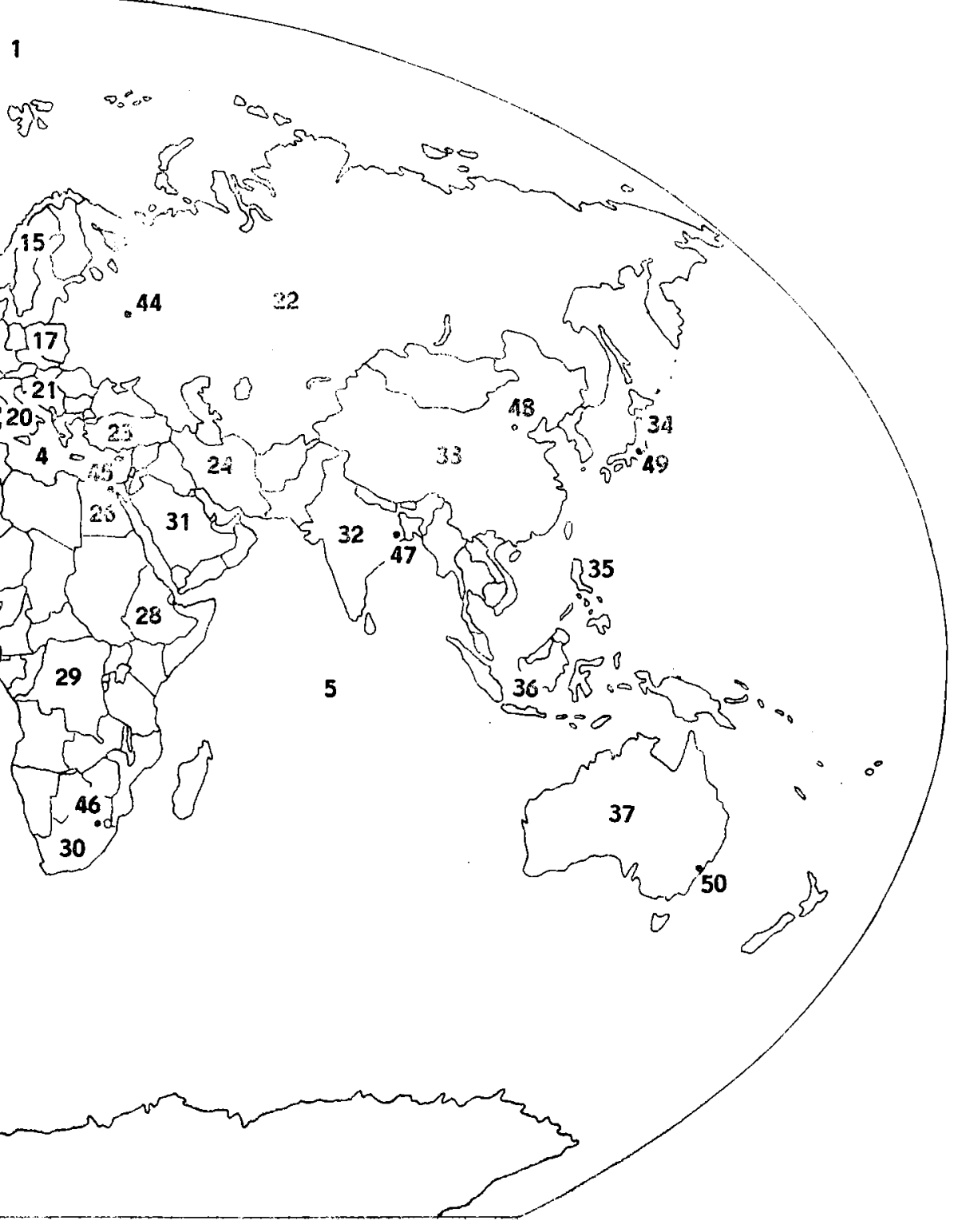



taking of studies seeking other correlations, e.g., test results and the index of intellect of subjects and education of the parents.

(6) We suggest that the testing of a large sample (with a minimum of 300 subjects) should be synchronized with testing procedures using small groups of $4-5$ subjects. The examinations should use a laboratory technique where each subject of the group resolves the test separately in order to obtain detailed information about the perception of the map and reason for the mistakes.

(7) We suggest that, during further testing, a group of 20-30 subjects who have been identified as doing well in geography could provide a base comparison (control group) for the achievement in the total sample.

(8) We suggest that in this type of testing, maps of various cartographic projections and scales should also be used. The consideration of this suggestion would give a possibility of stating which mistakes made by the subjects might result from a lack of information and poor orientation on the map, and which from defects of the map.

II. PLACE VOCABULARY PROJECT PHASE II TO BE REPORTED AT THE SYMPOSIUM ON GEOGRAPHIC EDUCATION IN FREIBURG, AUGUST 1984

Purpose: to investigate the place vocabularies of senior citizens in various parts of the United States and elsewhere around the world.

Correlation to be sought:

1) with 13 year-olds previously tested

2) with

a) income level

b) education level

c) occupation

3) male/female

4) urban/rural

5) TV viewing habits

6) reading habits

7) voting habits

8) cross regional

9) cross cultural

Major outcome: the identification of factors which contribute to the storage, retention, and retrieval of place names in long-term memory.

Sample population desired: a broad cross section of senior citizens (age 65 yrs. and above) from various geographical areas and walks of life. 
Time schedule: 'The testing portion was done From June to December 1983. A time limit of 50 minutes is considered the maximum for taking the test unless a person has vision difficulties.

Methodology: Volunteer test coordinators will administer a. minimum of six teists to a sample of their choice. The graded test with a descriptive covering letter will be sent to the Place Vocabulary Project at the University of Georgia for further correlations and the writing of a report. All test coordinators will be identified and will receive copies of the final report.

Table 1

Range of Score

\begin{tabular}{|l|c|c|c|c|c|c|}
\hline \multicolumn{1}{|c|}{ Country } & $\mathbf{0 - 1 0}$ & $\mathbf{1 1 - 2 0}$ & $\mathbf{2 1 - 3 0}$ & $\mathbf{3 1 - 4 0}$ & $\mathbf{4 1 - 5 0}$ & $\begin{array}{l}\text { mean } \\
\text { score }\end{array}$ \\
\hline Canada & 9.5 & 21.7 & 27.5 & 23.8 & 17.5 & 26.4 \\
U.S.A. & 15 & $\mathbf{2 5}$ & $\mathbf{2 2}$ & 21 & 14 & 24.7 \\
Mexico & 14.1 & 30.8 & 29.7 & 18.2 & 7.2 & 23.3 \\
Venezuela & 30.3 & 25.7 & 24.2 & 13.3 & 6.5 & 19.5 \\
Brazil & 42.4 & 24.8 & 13.0 & 13.4 & 6.4 & 13.7 \\
Norway & 9.0 & 13.2 & 14.6 & 20.2 & 43.1 & 33.5 \\
Ireland & 12.0 & 12.9 & 29.7 & 26.0 & 19.4 & 28.34 \\
Netherlands & 5.2 & 8.8 & 16.9 & 25.4 & 43.7 & 30.3 \\
Poland & 9.9 & 1.3 & 10.3 & 15.6 & 71.8 & \\
Nigeria & 33.0 & 29.3 & 28.3 & 7.4 & 2.0 & 16.1 \\
India & 6.7 & 12.0 & 34.3 & 2.9 .1 & 17.9 & 32.3 \\
Japan* & 3.9 & 8.6 & 18.5 & 39.4 & 30.5 & \\
New Zealand* & 3.7 & 15.7 & 17.0 & 34.3 & 29.6 & \\
Intermational School, & & & & & & \\
Iraq* & 11.1 & 7.4 & 7.4 & 25.9 & 48.2 & $\mathbf{3 5 . 4}$ \\
\hline
\end{tabular}

* limited sample

Appendix

\section{WORLD CITIZENS BASIC PLACE VOCABULARY TEST}

School Student

Class Male Female

Date Birthdate

1. About how many hours do you watch television in a week?

2. Is geography one of the courses you are taking now? Yes No ........

3. What is the most distant place from here which you have visited? Write the numbers from the map in front of the correct name below.

Oceans and Seas (numbers 1-5)

$\begin{array}{ll}\text { - Arctic Ocean } & \text { - Caribben Sea - Mediterranean Sea } \\ \text { - Atlantic Ocean } & \text { - Indian Ocean }\end{array}$


Countries (numbers 6-37)

- Algeria

- Argentina

- Australia

- Brazil

- Canada

- Chile

- China

- Colombia

- Cuba

- Egypt

- Ethiopia

Cities (numbers 38-50)

- Buenos Aires

- Cairo

- Calcutta

- Johaninesburg
- France

- India

- Indonesia

- Iran

- Italy

- Japan

- Mexico

- Nigeria

- Peru

- Philippines

- Poland

- London

- Mexico City

- Moscow

- New York
- Saudi Arabia

- South Africa

- Spain

- Sweden

- Turkey

- United Kingdom

- USSR (Soviet Union)

- United States

- Yug əslavia

- Zaire

- Paris

- Peking

- Rio de Janeiro

- Sydiney

- Tokyo 
